\title{
SISTEM INFORMASI ADMINISTRASI LAYANAN SURAT ONLINE DESA WESKUST KABUPATEN KEPAHIANG
}

\author{
Sarkawi ${ }^{1}$, Andilala ${ }^{2}$ \\ ${ }^{1}$ Jurusan Promosi Kesehatan, Poltekkes Kemenkes Bengkulu \\ ${ }^{2}$ Program Studi Sistem Informasi, Fakultas Teknik, Universitas Muhammadiyah Bengkulu \\ mustawie@gmail.com ${ }^{1}$, andilala@umb.ac.id ${ }^{2}$
}

\begin{abstract}
The rapid use of information technology today has made the government more aware of the benefits of using information technology, especially in the internet sector. The high use of the internet is inseparable from the emergence of various website applications developed by the community, entrepreneurs, including government agencies. The Central Government strongly supports the creation of various kinds of community service websites as an effort to keep the wheels of government running. The development of this community service website is an effort to prevent crowds at public service facilities which currently need to be avoided to prevent the transmission of the Covid-19 outbreak, which recently has not shown a significant decline. In terms of community services in rural areas, the central government also understands and encourages village governments to have village websites that can be used to empower villages and village communities, this is evidenced by the launch of the desa.id domain extension as an official domain extension and is devoted to websites. Village website development is also a government priority program contained in Permendesa Number 11 of 2019 concerning Priority for the Use of Village Funds in 2020 in Appendix I CHAPTER I Letter E concerning Priority List in the Village Development Sector, Point d concerning Procurement, Development, utilization and maintenance of facilities and infrastructure information and communication and item 2 mentions the creation of a village website. This shows that the central government is really serious so that villages can develop website-based services and information. Weskust Village is one of the villages located in Kepahiang District, Kepahiang Regency, Bengkulu Province. The constraints experienced by the Weskust village government today are the limited access to information that can be seen and accessed by the village community in particular and the surrounding community in general, especially access to information on village activities, village administration, superior village products and village locations. Based on these problems, it encourages the author to create a website and administrative application for the Weskut village. With the existence of a village website and an online village administration application it is hoped that in providing services to the community it can be maximized, and access to information about the village of Weskust can be accessed and seen by anyone and from anywhere while an internet network is still available.
\end{abstract}

Keywords: Village Web, Online Surat, Kepahiang Weskust Village

Abstrak - Pesatnya penggunaan teknologi informasi saat ini membuat pemerintah semakin menyadari manfaat penggunaan teknologi informasi terutama bidang internet. Tingginya penggunaan internet tidak terlepas dari munculnya berbagai aplikasi website baik yang dikembangkan oleh masyarakat, kalangan pengusaha, termasuk instansi pemerintah. Pemerintah Pusat sangat mendukung dibuatnya berbagai macam website layanan masyarakat sebagai upaya tetap berjalannya roda pemerintahan. Pengembangan website layanan masyarakat ini sebagai upaya mencegah adanya kerumunan di fasilitas layanan umum yang saat ini perlu dihindari untuk mencegah penularan wabah Covid-19 yang akhir-ahkhir ini belum menunjukan penurunan yang signifikan. Dalam hal pelayanan masyarakat di pedesaan, pemerintah pusat juga memahami dan mendorong pemerintah desa untuk memiliki website desa yang dapat digunakan untuk memberdayakan desa dan masyarakat desa, hal ini dibuktikan dengan telah diluncurkanya ekstensi domain desa.id sebagai ekstensi domain resmi dan dikhususkan untuk website. Pengembangan website desa juga merupakan program prioritas pemerintah yang tertuang didalam Permendesa Nomor 11 Tahun 2019 tentang Prioritas Penggunaan Dana Desa Tahun 2020 pada Lampiran I BAB I Huruf E tentang Daftar Prioritas Bidang Pembangunan Desa, Point d tentang Pengadaan, Pembangunan, pemanfaatan dan Pemeliharaan sarana dan prasarana informasi dan komunikasi dan Butir ke 2 menyebutkan tentang pembuatan website desa. Hal ini menunjukkan bahwa pemerintah pusat benar-benar serius agar desa dapat mengembangkan layanan dan informasi berbasis website. Desa Weskust merupakan salah satu desa yang terdapat di Kecamatan Kepahiang Kabupaten Kepahiang Propinsi Bengkulu. Kendala yang dialami oleh Pemerintah desa weskust sekarang ini adalah terbatasnya akses informasi yang dapat di lihat dan diakses oleh masyarakat desa khususnya dan masyarakat sekitar pada umumnya, terutama akses informasi kegiatan-kegiatan desa, administrasi desa, produk unggulan desa dan lokasi desa. Berdasarkan adanya permasalahan tersebut mendorong Penulis untuk membuatkan website dan aplikasi administrasi untuk desa weskut. Dengan adanya Website desa dan aplikasi administrasi desa online di harapakan agar dalam melakukan pelayanan kepada masyarakat dapat lebih maksimal, dan akses informasi tentang desa weskust dapat diakses dan dilihat oleh siapa saja dan dari mana saja selagi masih tersedia jaringan internet.

Kata Kunci : Web Desa, Surat Online, Desa Weskust Kepahiang 


\section{Pendahuluan}

Perkembangan teknologi komunikasi dan informasi terutama internet saat ini membawa kemajuan yang sangat pesat di berbagai bidang kehidupan. Dengan adanya website membantu banyak pihak dari individu, organisasi, pemerintah bahkan swasta untuk bisa menghadirkan informasi terkini melalui media digital. Hal ini pun yang semakin menjadi perhatian khusus bagi pemerintah desa untuk mengembangkan pelayanan dan meningkatkan berbagai aspek kehidupan masyarakat. Ada banyak manfaat website untuk desa yang dapat membantu kemajuan desa tersebut

Pemerintah kini semakin menyadari besarnya manfaat website untuk desa, hal ini dibuktikan dengan peluncuran ekstensi domain desa.id sebagai ekstensi domain resmi dan dikhususkan untuk website desa, bukti dukungan pemerintah tersebut juga tertuang didalam Peraturan Menteri Desa, Pembangungan Daerah Tertinggal dan Transmigrasi (Permendesa) Republik Indonesia Nomor 11 Tahun 2019 [1] tentang Prioritas Penggunaan Dana Desa Tahun 2020 pada Lampiran I BAB I Huruf E tentang Daftar Prioritas Bidang Pembangunan Desa, Point $\mathrm{d}$ tentang Pengadaan, Pembangunan, pemanfaatan dan Pemeliharaan sarana dan prasarana informasi dan komunikasi Butir ke 2 menyebutkan tentang pengadaan website desa. Hal ini menunjukkan bahwa pemerintah pusat benar-benar serius agar desa dapat mengembangkan layanan dan informasi berbasis website.

Desa Weskust merupakanh salah satu desa yang terdapat di Kecamatan Kepahiang Kabupaten Kepahiang Propinsi Bengkulu. Kendala yang dialami oleh Pemerintah desa weskust sekarang ini adalah terbatasnya akses informasi yang dapat di lihat dan diakses oleh masyarakat desa khusunya dan masyarakat sekitar pada umumnya, terutama akses informasi bidang strukturtur organisasi desa, kegiatan-kegiatan desa, administrasi desa, produk unggulan desa, lokasi desa dan belum maksimalnya layanan yang di berikan kepada masyarakat terutama dalam hal pelayanan surat menyurat yang di butuhkan oleh masyarakat, dengan adanya permasalahan tersebut mendorong Penulis untuk membuatkan website dan aplikasi administrasi untuk desa weskut dengan tujuan untuk menyelesaikan permasalahan tersebut.

Dengan adanya Website desa dan aplikasi administrasi desa online di harapakan agar dalam melakukan pelayanan kepada masyarakat dapat lebih maksimal, Dan akses informasi tentang desa weskust dapat diakses dan dilihat dari mana saja selagi masih tersedia jaringan internet.

\section{Landasan Teori}

\section{a. Sistem Informasi}

Sistem Informasi adalah gabungan dari perangkat lunak (software), perangkat keras (hardware),infrastuktur, dan Sumber Daya Manusia (SDM) yang terlatih. Keempat bagian utama ini saling berkaitan untuk menciptakan sebuah sistem yang dapat mengolah data menjadi informasi yang bermanfaat. Di dalamnya juga termasuk proses perencanaan, kontrol, koordinasi, dan pengambilan keputusan. Sehingga, sebagai sebuah sistem yang mengolah data menjadi informasi yang akan disajikan dan digunakan oleh pengguna, maka sistem informasi merupakan sebuah sistem yang kompleks [2].

\section{b. Pengertian Surat}

Surat adalah suatu sarana untuk menyampaikan pernyataan atau informasi secara tertulis dari pihak yang satu kepada pihak yang lain. Yang berupa secarik kertas dan sebagainya sebagai tanda atau keterangan [3].

a) Surat menurut [4] adalah lembaran kertas yang ditulis atas nama pribadi penulis, atau atas nama kedudukannya dalam organisasi, yang ditujukan kepada alamat tertentu yang memuat informasi.

b) surat adalah pernyataan tertulis dari pihak satu ke pihak lain, atas nama perseorangan ataupun atas nama jabatan. Surat adalah sehelai kertas atau lebih yang digunakan untuk mengadakan komunikasi atau hubungan secara tertulis [5].

c) Menurut [6] surat adalah alat komunikasi tertulis yang berasal dari suatu pihak dan ditujukan kepada pihak lain untuk menyampaikan warta. Dari berbagai definisi diatas dapat disimpulkan mengenai pengertian surat yaitu sarana komunikasi yang berupa berita, ide, pendapat, laporan dan permintaan yang ditujukan kepada orang lain atau instansi atas nama sendiri ataupun kedinasan.

\section{c. Web Server}

Web server adalah Perangkat lunak yang mengelola (mengatur) permintaan user dari browser dan hasilnya dikembalikan kembali ke browser [7]

\section{d. Website}

Website (situs web) adalah keseluruhan halaman-halaman web yang terdapat dalam sebuah domain yang mengandung informasi. Sebuah website biasanya dibangun atas banyak halaman web yang saling berhubungan. Hubungan antara satu halaman web dengan halaman web yang lainnya disebut dengan hyperlink, sedangkan teks yang dijadikan media penghubung disebut hypertext [8].

\section{e. Domain Name}

Sebagaikomponen penting dari infrastruktur Internet, Domain Name System (DNS) adalah 
sistem penerjemah yang mengubahnama host Internet (nama domain) ke seri yang unik dari nomor yang merupakan suatu Internet Protocol (IP) addresses untuk setiap nama domain yang spesifik. Mirip dengan nomor telepon, alamat IP yang diperlukan untuk rute paket dan berkoordinasi ke seluruh sistem Internet [4].

\section{Metode Penelitian}

Model Pengembangan sistem ini menggunakan model incremental

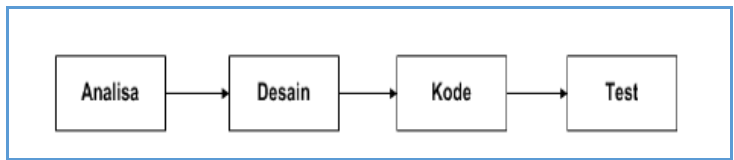

Gambar 1. Model Increamental

\section{A. Analisis Sistem}

Pada penelitian ini untuk mendapatkan data penulis menggunakan metode pengumpulan data dengan cara wawancara, observasi dan study pustaka.

\section{B. Desain Sistem}

Pada penelitian ini desain sistem yang di gunakan adalah:

1. Diagram Alir Data (DFD)

DFD menggambarkan model sistem sebagai jaringan kerja antar fungsi yang saling berhubungan. Pada DFD terlihar aliran data dari sistem ke media database.

\section{a. Diagram Konteks}

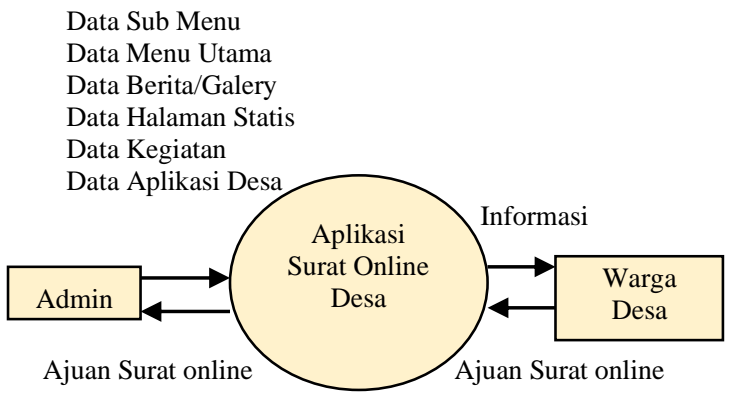

Gambar 2. Diagram Konteks

\section{b. DFD Level 0}

DFD Level 0 menggambarkan akses yang dilakukan oleh Admin dan user dalam penggunaan sistem dan proses aliran data yang terjadi.

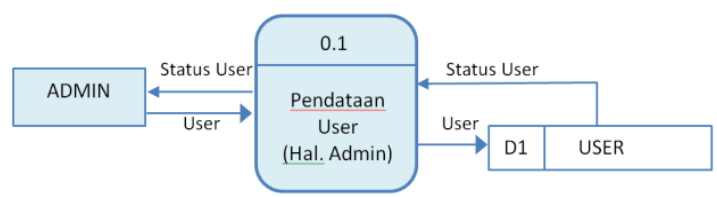

Gambar 3. DFD Level 0 c. DFD Level 1 Proses 1

DFD level 1 proses 1 Penambahan Data User menggambarkan akses sistem yang dilakukan oleh admin, serta proses aliran datanya.

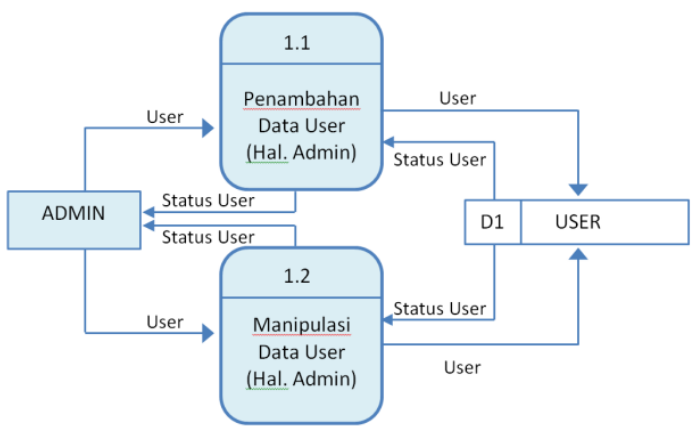

Gambar 4. DFD Level 1 Proses 1 Penambahan Data User

d. DFD Level 1 Proses 2

DFD level 1 proses 2 Permohonan Surat Keterangan menggambarkan akses sistem yang dilakukan oleh user (warga), serta proses aliran datanya.

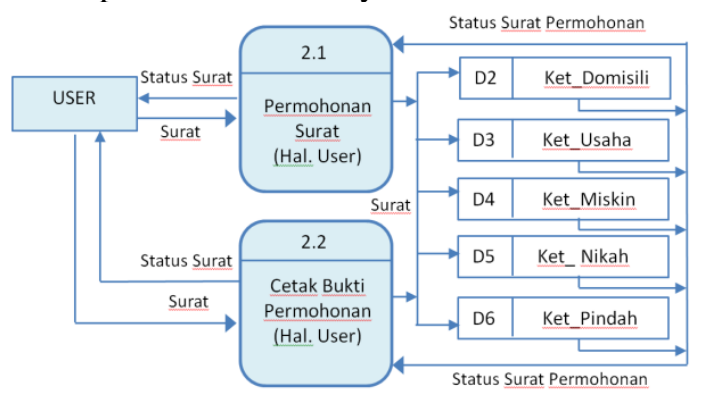

Gambar 5. DFD Level 1 Proses 2 Permohonan Surat Keterangan

e. DFD Level 1 Proses 3

DFD level 1 proses 3 Validasi dan Cetak Surat menggambarkan akses sistem yang dilakukan oleh Admin, serta proses aliran datanya dalam memvalidasi data permohonan dan cetak surat keterangan.

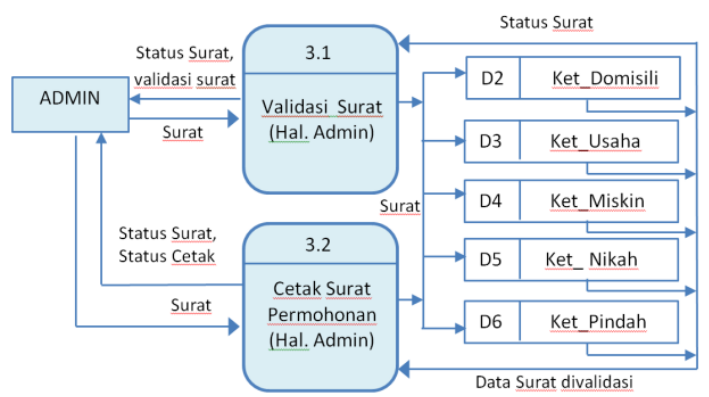

Gambar 6. DFD Level 1 Proses 3 Validasi dan Cetak Surat

2. Rancangan Tabel

Data yang diinput oleh pengguna (user) selanjutnya akan disimpan dalam sebuah file yang kemudian dapat dipanggil untuk dilakukan 
pembenaran (edit) data maupun pencetakan. Tabel yang diperlukan adalah sebagai berikut:

a. Tabel User

Table user digunakan untuk menyimpan data User dalam hal ini Admin dan Warga Desa, Warga desa per KK mendapatkan user untuk kebutuhan angota keluarga.

\begin{tabular}{|l|l|l|}
\hline Key & Nama Field & Tipe/Ukuran \\
\hline PK & id & int(11) \\
\hline & nama_lengkap & varchar(35) \\
\hline & username & varchar(55) \\
\hline & password & varchar(55) \\
\hline & email & varchar(55) \\
\hline & level & enum('admin', 'user') \\
\hline & blokir & enum('Y', 'N') \\
\hline & id_session & varchar(55) \\
\hline & created_at & datetime \\
\hline & update_at & datetime \\
\hline
\end{tabular}

b. Tabel Domisili

Tabel domilisi digunakan untuk menyimpan data permohonan domisili dari warga desa yang membutuhkan Surat Keterangan Domisili.

\begin{tabular}{|l|l|l|}
\hline Key & Nama Field & Tipe/Ukuran \\
\hline PK & id & int(11) \\
\hline & nama_lengkap & varchar(80) \\
\hline & tempat_lahir & varchar(80) \\
\hline & tanggal_lahir & date \\
\hline & jenis_kelamin & varchar(40) \\
\hline & agama & varchar(40) \\
\hline & status & varchar(40) \\
\hline & alamat & text \\
\hline & no_ktp & varchar(40) \\
\hline & nama_pekerjaan & varchar(85) \\
\hline
\end{tabular}

c. Tabel Usaha

Tabel usaha digunakan untuk menyimpan data permohonan Keteranga Usaha dari warga desa yang membutuhkan Surat Keterangan Usaha.

\begin{tabular}{|l|l|l|}
\hline Key & Nama Field & Tipe/Ukuran \\
\hline PK & id & int(11) \\
\hline & nama_lengkap & varchar(80) \\
\hline & tempat_lahir & varchar(80) \\
\hline & tanggal_lahir & date \\
\hline & jenis_kelamin & varchar(40) \\
\hline & agama & varchar(40) \\
\hline & tempat_usaha & varchar(80) \\
\hline & status & varchar(40) \\
\hline
\end{tabular}

\begin{tabular}{|l|l|l|}
\hline & alamat & text \\
\hline & no_ktp & varchar(40) \\
\hline & nama_pekerjaan & varchar(85) \\
\hline & nama_usaha & varchar(80) \\
\hline
\end{tabular}

\section{d. Tabel Ket_Miskin}

Tabel ket_miskin digunakan untuk menyimpan data permohonan Keterangan Miskin (Prasejahtera) dari warga desa yang membutuhkan Surat Keterangan Miskin.

\begin{tabular}{|l|l|l|}
\hline Key & Nama Field & Tipe/Ukuran \\
\hline PK & id & int(11) \\
\hline & nama_lengkap & varchar(80) \\
\hline & tempat_lahir & varchar(80) \\
\hline & tanggal_lahir & date \\
\hline & jenis_kelamin & varchar(40) \\
\hline & agama & varchar(40) \\
\hline & alamat & text \\
\hline & no_ktp & varchar(40) \\
\hline & nama_pekerjaan & varchar(85) \\
\hline & nama_desa & varchar(80) \\
\hline & status & varchar(40) \\
\hline
\end{tabular}

\section{e. Tabel Nikah}

Tabel nikah digunakan untuk menyimpan data permohonan keterangan nikah dari warga desa yang membutuhkan.

\begin{tabular}{|l|l|l|}
\hline Key & Collation & Attributes \\
\hline PK & id & int(11) \\
\hline & nama_lengkap & varchar(80) \\
\hline & tempat_lahir & varchar(80) \\
\hline & tanggal_lahir & date \\
\hline & jenis_kelamin & varchar(40) \\
\hline & agama & varchar(40) \\
\hline & bangsa & varchar(80) \\
\hline & status_pria & varchar(40) \\
\hline & status_wanita & varchar(40) \\
\hline & alamat & text \\
\hline & no_ktp & varchar(40) \\
\hline & nama_pekerjaan & varchar(85) \\
\hline & nama_ayah & varchar(80) \\
\hline & no_ktp_ayah & varchar(40) \\
\hline & tempat_lahir_ayah & varchar(80) \\
\hline & tanggal_lahir_ayah & date \\
\hline & agama_ayah & varchar(40) \\
\hline & bangsa_ayah & varchar(80) \\
\hline & alamat_ayah & text \\
\hline & pekerjaan_ayah & varchar(85) \\
\hline & &
\end{tabular}




\begin{tabular}{|l|l|l|}
\hline & nama_ibu & varchar(80) \\
\hline & no_ktp_ibu & varchar(40) \\
\hline & tempat_lahir_ibu & varchar(80) \\
\hline & tanggal_lahir_ibu & date \\
\hline & agama_ibu & varchar(40) \\
\hline & bangsa_ibu & varchar(80) \\
\hline & alamat_ibu & text \\
\hline & pekerjaan_ibu & varchar(85) \\
\hline
\end{tabular}

f. Tabel Keterangan Pindah

Tabel keterangan pindah digunakan untuk menyimpan data permohonan keterangan pindah dari warga desa yang membutuhkan.

\begin{tabular}{|l|l|l|}
\hline Key & Nama Field & Tipe/Ukuran \\
\hline PK & id & int(11) \\
\hline & nama_lengkap & varchar(80) \\
\hline & tempat_lahir & varchar(80) \\
\hline & tanggal_lahir & date \\
\hline & jenis_kelamin & varchar(40) \\
\hline & agama & varchar(40) \\
\hline & alamat & text \\
\hline & no_ktp & varchar(40) \\
\hline & nama_pekerjaan & varchar(85) \\
\hline & tujuan_pindah & varchar(80) \\
\hline & status & varchar(40) \\
\hline
\end{tabular}

\section{IV.Hasil dan Pembahasan}

\section{A. Hasil}

Pengembangan website desa weskust Kapubaten Kepahiang meliputi informasi desa berupa profil desa, data administratif \& data penduduk desa, potensi desa, kolom desa dan berita desa yang dilengkapi dengan Surat Online yang digunakan untuk permohonan penerbitan Surat Keterangan Domisili, Keterangan Usaha, Keterangan Nikah, Keterangan Miskin dan Keterangan Pindah. Tampilan utama dari website desa weskust adalah seperti pada Gambar 7.

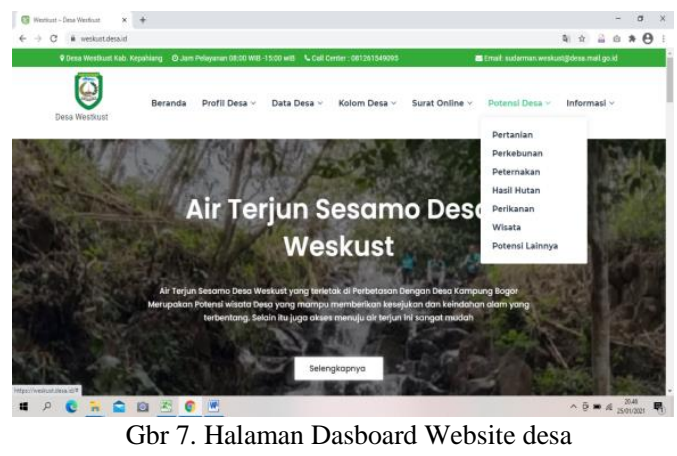

Pada tampilan utama website desa weskust terdapat beberapa menu, untuk menggunakan layanan surat online pilih menu surat online, didalam menu tersebut terdapat dua sub menu, yaitu sub menu formulir surat permohonan dan sub menu persyaratan perizinan. Pilih menu formulir surat permohonan maka akan tampil menu login seperti Gambar 8.

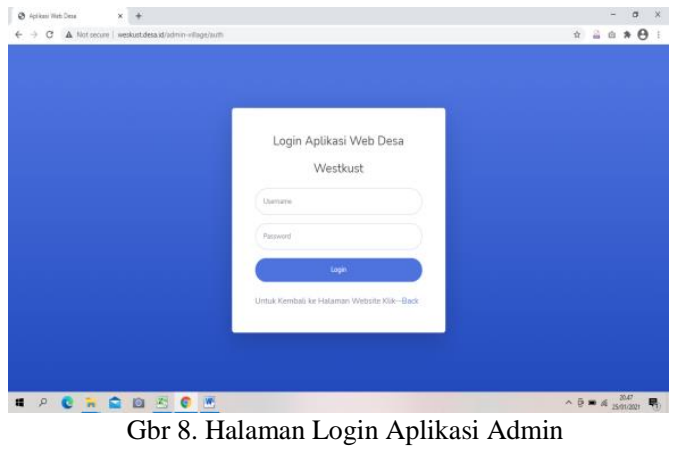

Dengan menginputkan username dan pasword yang sudah di berikan maka akan tampil beranda admin seperti Gambar 9.

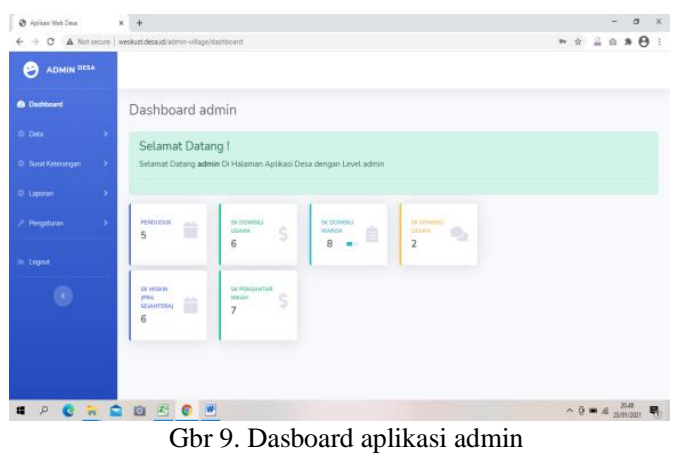

Pada menu data penduduk dapat di gunakan untuk menginputkan nama-nama penduduk yang ada di desa, tampilan menu input data penduduk seperti pada Gambar 10.

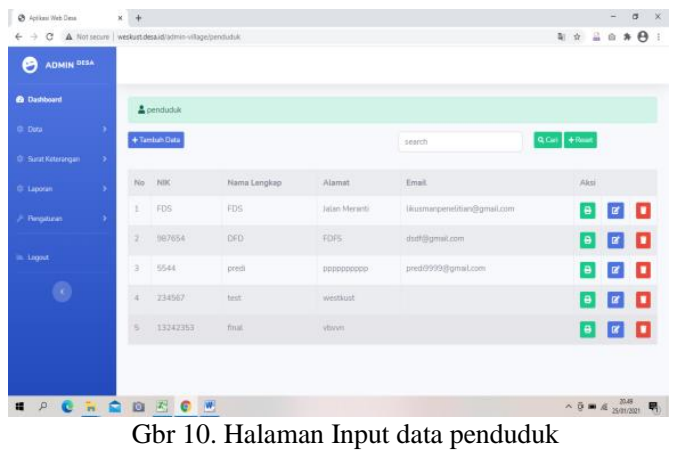

Pada beranda admin juga terdapat menu yang dapat digunakan untuk pengaturan user, dimana setiap Kepala Keluarga (KK) akan mendapatkan satu username dan pasword yang nantinya dapat di gunakan pada waktu mengajukan surat keterangan yang di perlukan. 
Halaman pengaturan untuk user seperti terlihat pada Gambar 11.

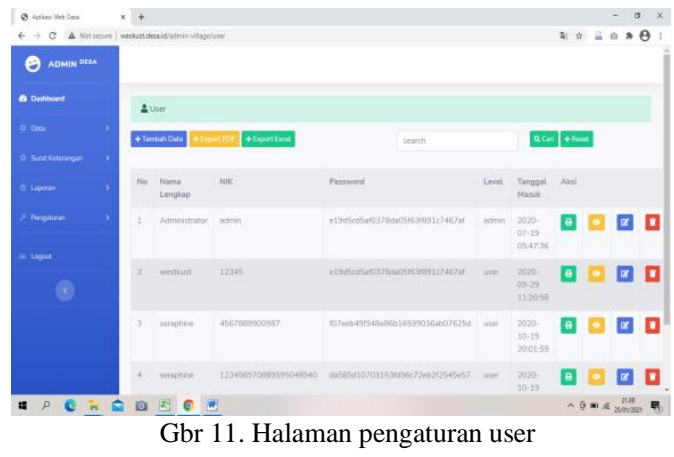

Setelah masing-masing user/kepala keluarga mendapatkan username dan pasword dari admin desa, selanjutnya user dapat menggunakan aplikasi surat online, langkah untuk masuk ke aplikasi surat online adalah user membuka alamat website desa yaitu https://weskust.desa.id/ pada beranda website tersebut terdapat menu surat online lalu pilih formulir surat permohonan selanjutnya akan tampil menu login seperti di Gambar 12.

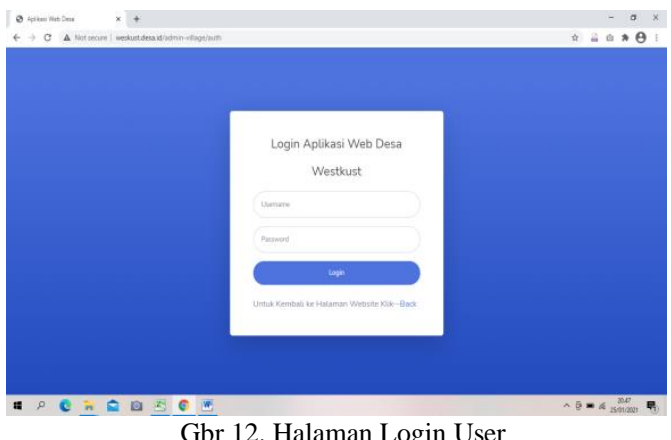

Inputkan username dan pasword yang telah di berikan oleh admin desa lalu klik login, jika tidak ada kesalahan maka akan tampil beranda user seperti Gambar 13.

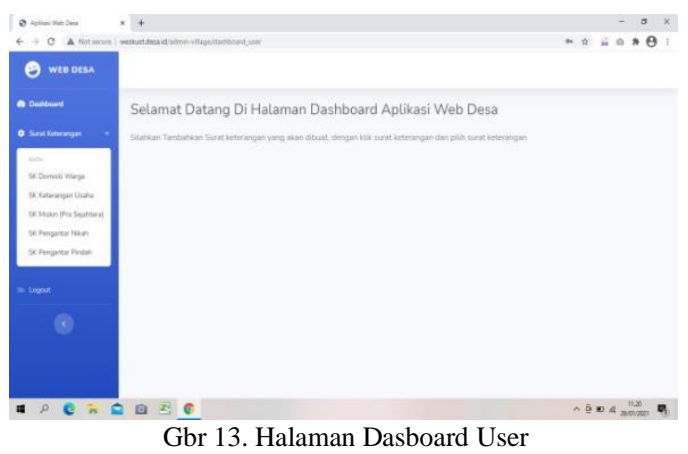

Di beranda user terdapat menu surat keterangan yang di dalamnya terdapat beberapa sub menu seperti Surat Keterangan (SK) domisili warga, SK Usaha, SK Miskin/Keluarga (Prasejahtera), SK Pengantar Nikah, SK Pindah. Untuk mengajukan surat sesuai dengan kebutuhan pilih salah satu sub menu yang telah tampil. Sebagai cohtoh, ketika user akan mengajukan surat keterangan domisili, maka pilih (Klik) sub menu SK keterangan Domisili maka akan tampil formulir seperti Gambar 14.

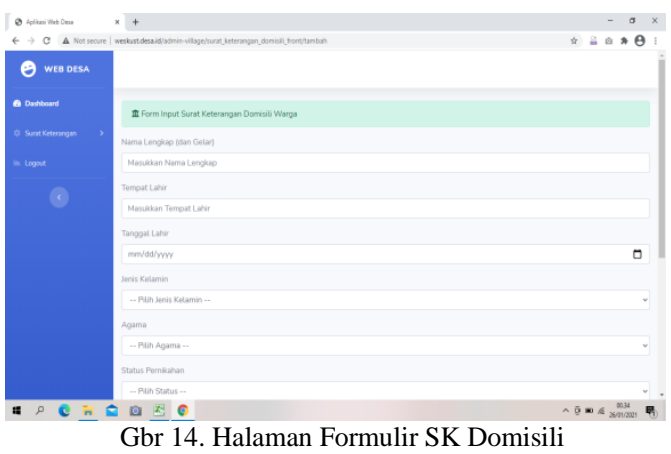

Pada Form seperti pada Gambar 14, user dapat mengisi data sesuai dengan identitas yang dimiliki. klik simpan agar data tersimpan, untuk melihat atau mencetak surat yang telah di ajukan, pada beranda user sub menu SK Domisili klik gambar printer, maka akan tampil surat yang di ajukan seperti terlihat pada Gambar 15.

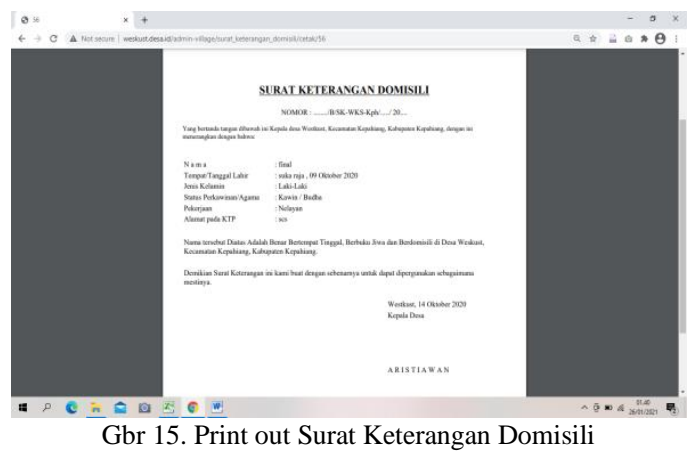

Untuk mengajukan Surat Keterangan Usaha, user dapat memilih pada Dashboard Surat Keterangan - SK Keterangan Usaha. Perintah yang digunakan sama seperti langkah permohonan Surat Domisili. Begitu juga dengan permohonan surat lainnya. Formulir Input Surat Keterangan usaha terlihat seperti pada Gambar 16.

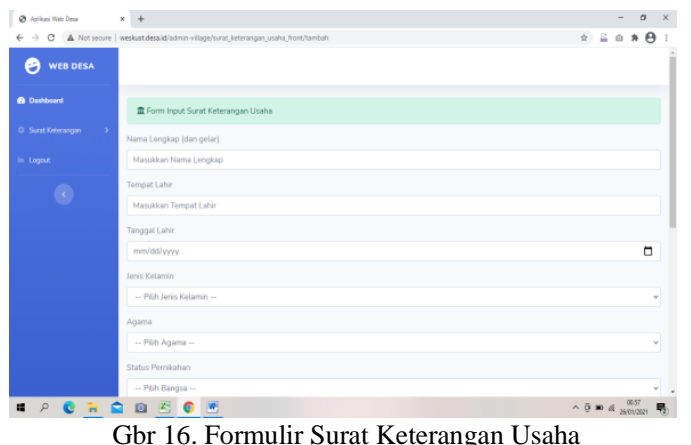

Gbr 16. Formulir Surat Keterangan Usaha 
Tampilan Printout Surat Keterangan Usaha terlihat seperti pada Gambar 17.

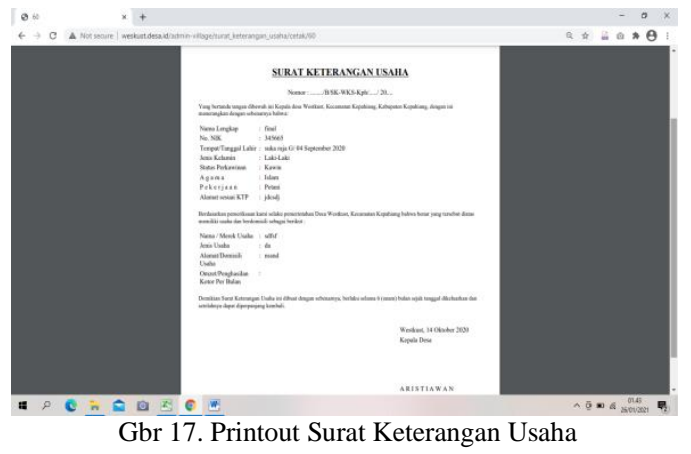

Formulir Input Surat Keterangan Miskin terlihat seperti pada Gambar 18.

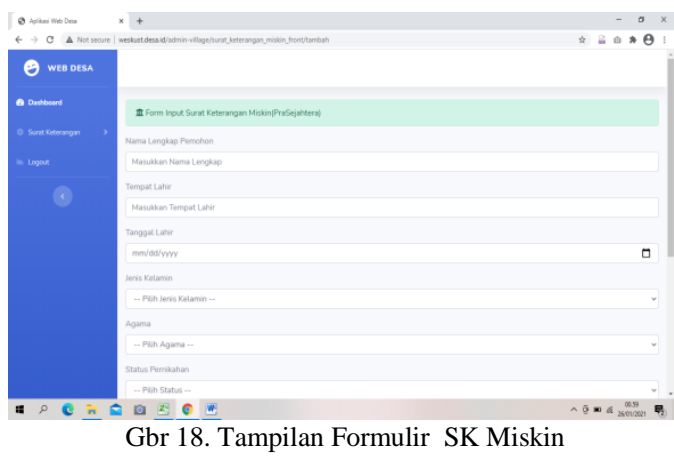

Tampilan Printout Surat Keterangan Miskin terlihat seperti pada Gambar 19.

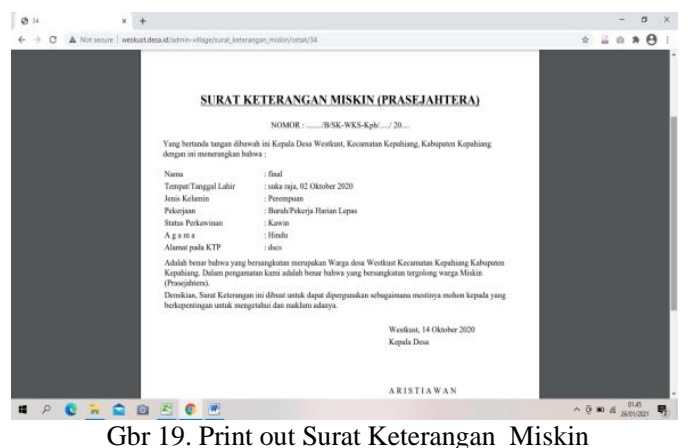

Formulir Input Surat Keterangan Pindah terlihat seperti pada Gambar 20.

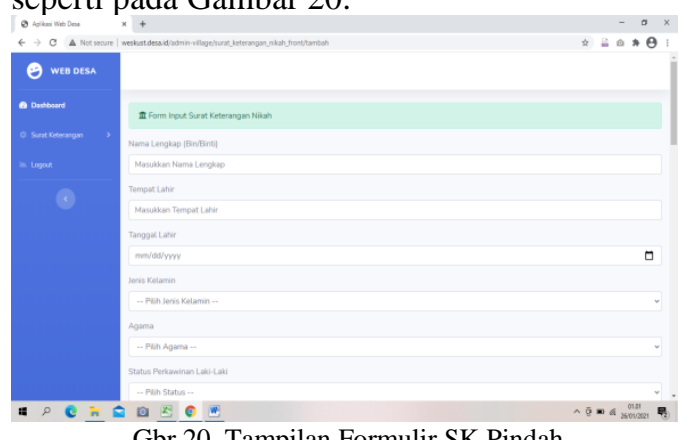

Gbr 20. Tampilan Formulir SK Pindah
Tampilan Printout Surat Keterangan Pindah terlihat seperti pada Gambar 21.

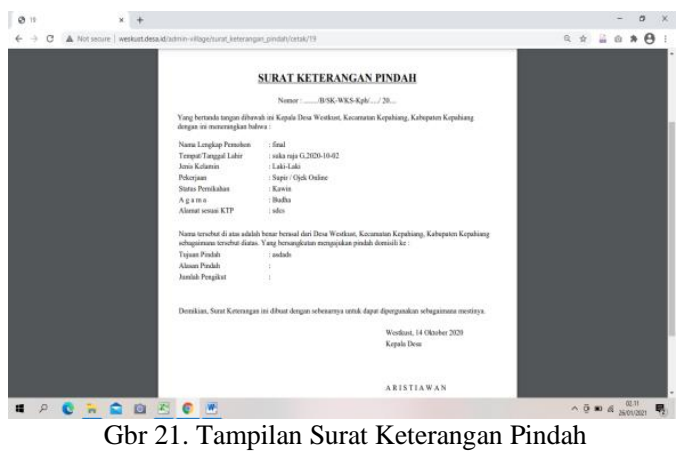

Formulir Input Surat Pengantar Nikah terlihat seperti pada Gambar 22.

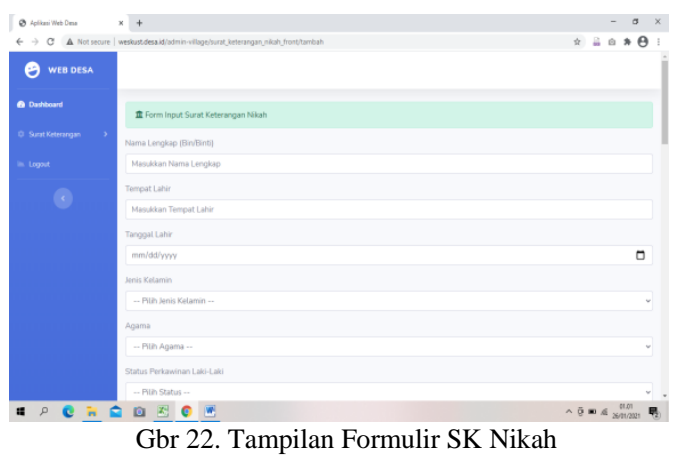

Tampilan Printout Surat Keterangan Nikah terlihat seperti pada Gambar 23.

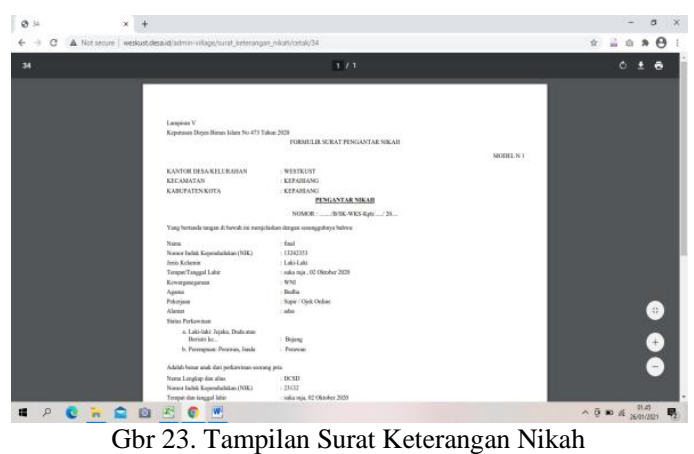

\section{B. Pembahasan}

Dari aplikasi surat online yang digunakan oleh user dalam hal ini penduduk desa dapat di ketahui rekapitulasi dari masing-masing surat yang telah di ajukan oleh masyarakat desa. Perangkat desa melalui Admin desa dapat melihat jumlah permohonan surat yang masuk. Rekapitulasi permohonan surat keterangan dapat dipilah berdasarkan Jenis Surat dan masa waktunya seperti per tanggal tertentu, per bulan tertentu atau per tahun tertentu. Dengan adanya laporan permohonan penerbitan Surat Keterangan dari Desa ini diharapkan akan terlihat animo masyarakat dalam memanfaatkan sistem Surat Online desa. 
Tampilan Printout laporan rekapitulasi Jumlah Penduduk seperti pada Gambar 24.

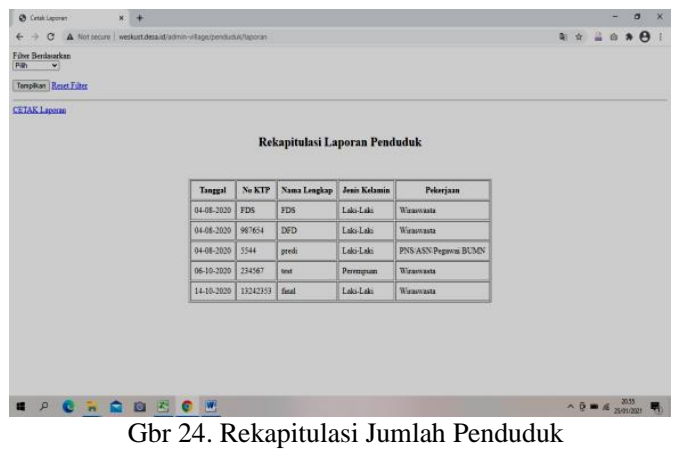

Tampilan laporan rekapitulasi permohonan SK Domisili seperti pada Gambar 25.

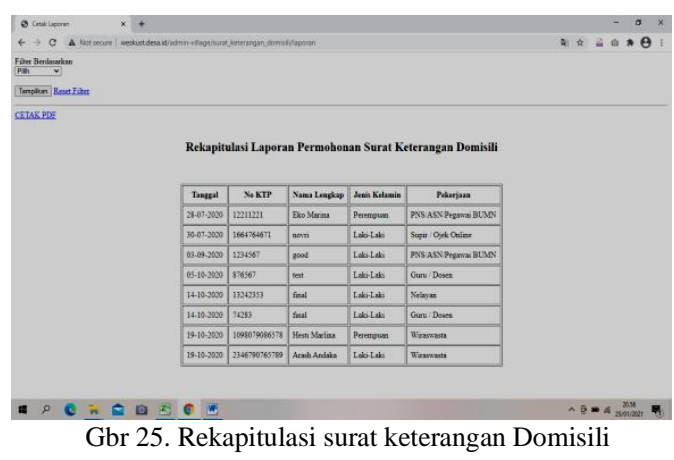

Tampilan laporan rekapitulasi permohonan SK Usaha seperti pada Gambar 26.

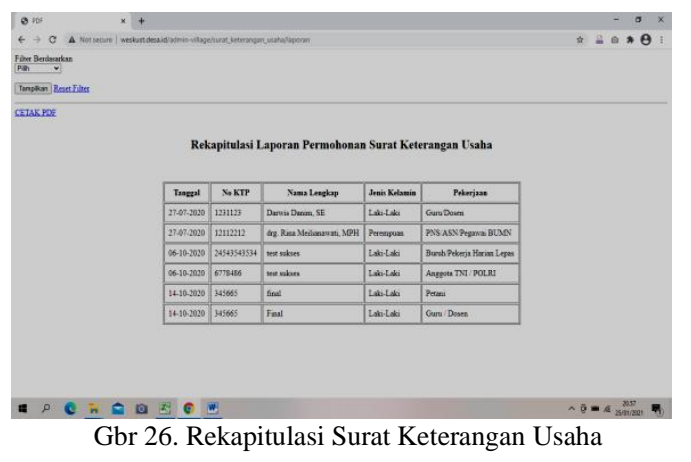

Tampilan laporan rekapitulasi permohonan SK Miskin (Prasejahtera) seperti pada Gambar 27.

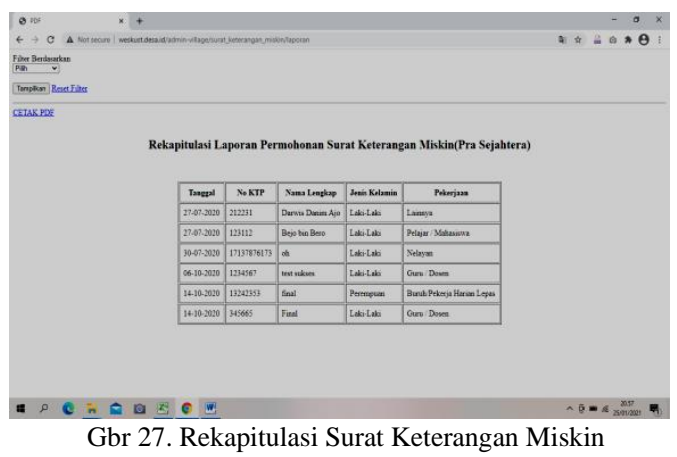

Tampilan laporan rekapitulasi permohonan Pengantar Nikah seperti pada Gambar 28.

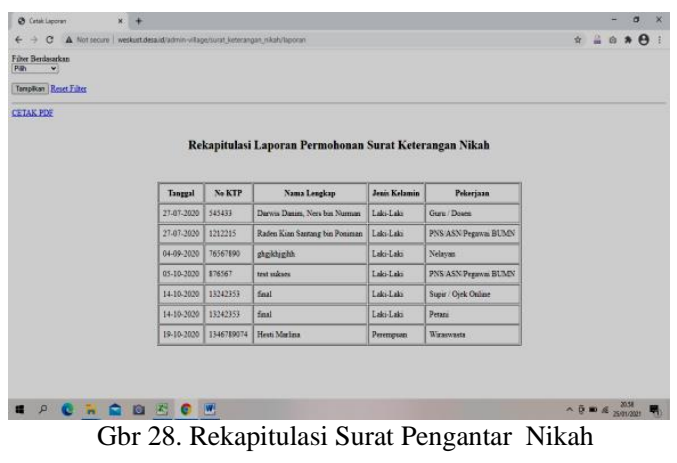

Tampilan laporan rekapitulasi permohonan SK Pindah seperti pada Gambar 29.

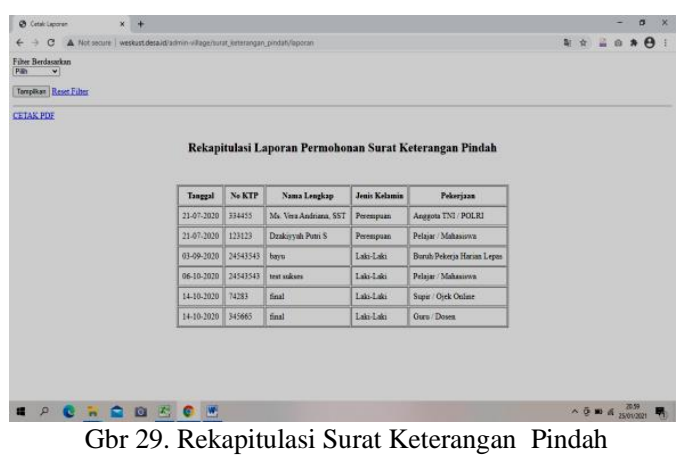

V. Kesimpulan dan Saran

a. Kesimpulan

Berdasarkan hasil penelitian bahwa membangun website desa dan Aplikasi administrasi surat online dapat menjadi solusi alternatif yang membantu pemerintah desa dalam mempromosikan produk unggulan desa dan dapat juga mempermudah penduduk dalam memngajukan surat, sehingga proses pengajuan surat lebih cepat dan mudah. Salah satu kelebihan dari aplikasi surat online ini adalah pihak pemerintah desa dapat lebih cepat mengetahui jumlah penduduk, penduduk yang mengajukan surat, dan jenis surat apa saja yang paling banyak di minta oleh penduduk berdasarkan rekapitulasi dari masing-masing jenis surat.

\section{b. Saran}

Surat Online yang dikembangkan dalam Website Desa Weskust ini hendaknya dapat disosialisasikan kepada warga desa. Sosiaslisai hendaknya dapat disampaikan kepada seluruh warga agar warga desa mengetahui fungsi dari conten Surat Online. Dimasa pandemi covid 19 saat ini masyarakat akan cenderung memanfaatkan Surat Onlie karena ada himbauan pemerintah untuk menjaga jarak. Pemanfaatan Surat Online secara baik juga akan mencegah dan melindungi warga dan perangkat Desa dari wabah Covid 19. 


\section{Referensi}

[1] Peraturan Menteri Desa, Pembangungan Daerah Tertinggal dan Transmigrasi (PERMENDESA) Republik Indonesia Nomor 11 Tahun 2019

[2] Agus Eka, Pratama, 2014, Sistem Informasi dan Implementasinya, Bandung: Informatika Bandung.

[3] Endang, Sri R.; Mulyani, Sri; Suyetty. 2016. Menangani Surat Masuk Dan Keluar (Mail Handling). Jakarta: Erlangga

[4] Ahmad, F, Indra, W. Rancang bangun sistem informasi pengelolaan dns secara terpusat (studi kasus cv. Surya putra perkasa), Jurnal INFOKAM Nomor I Th. XII/MARET/ 2016

[5] Rahardi, R. Kunjana. 2018. Surat Menyurat Dinas. Yogyakarta: Pustaka Book Publisher

[6] Ali, Adelan, Dkk. 2019. Panduan Lengkap Korespondensi. Jakarta: Easka Media.

[7] Basir, Barthos. 2016. Manajemen Kearsipan. Jakarta: PT Bumi Aksara.

[8] Bertha Sidik. 2014. Pemrograman Web dengan Php. Santika Kencana. Solo.

[9] Yuhefizar, Mooduto, \& Hidayat, R. (2015). Cara Mudah Membangun Website Interaktif Menggunakan Content Management System Joomla Edisi Revisi. Jakarta: PT Elex Media Komputindo 